\title{
Environmental Management Science Program (EMSP)
}

\section{Project number 69906 (issued as grant number FG07-99ER62875)}

\section{Research objective}

One of the major challenges in the field of radiation biology is to correlate the results of biochemical studies with the process of DNA repair as it occurs in the living cell. The overall goal of this project is to develop better methods for visualizing DNA doublestrand breaks and double-strand break repair complexes in situ, in irradiated cells. Technologies are particularly needed to study repair complexes induced by low doses of radiation, where only one or a few breaks may be present.

Our principal approach is to develop recombinant single chain antibodies, or scFvs, that recognize DNA repair proteins or other repair markers. Such antibodies contain antibody heavy and light chain genes fused through a flexible linker. They can be generated with precisely engineered specificities. We will use these antibodies to identify repair complexes in irradiated cells. We will stain for several markers simultaneously, and we will use image processing techniques to identify coincident signals. In this way, we hope to be able to reliably identify small numbers of events and screen out background noise.

\section{Research progress and implications}

As of June, 2001, we have carried out a number of experiments to identify suitable single chain antibodies and to develop protocols for their use. As a first step, we converted several known monoclonal antibodies to recombinant single chain form. Of these, the best characterized is $\mathrm{scFv} 18-2$, directed against the DNA-dependent protein kinase catalytic subunit, a protein that is essential for DNA double-strand break repair. The diagram below shows biochemical properties of scFv 18-2. The left panel, shows an SDS-PAGE analysis of this scFv, expressed in the E. coli periplasm. Unlike natural antibodies, which have a tetrameric structure and a native molecular weight of about $150,000 \mathrm{Da}$, this scFv is a single polypeptide of about 30,000 Da. Despite its small size, the recombinant $\mathrm{scFv}$ shares many desirable properties with the parental monoclonal antibody, including the ability to recognize its specific target in a complex mixture of proteins in an immunoblot (center panel) and the ability to bind tightly and specifically in an ELISA assay. We are currently using scFv 18-2 in immunofluorescence experiments, in order to optimize conditions for use of scFvs in this assay system.

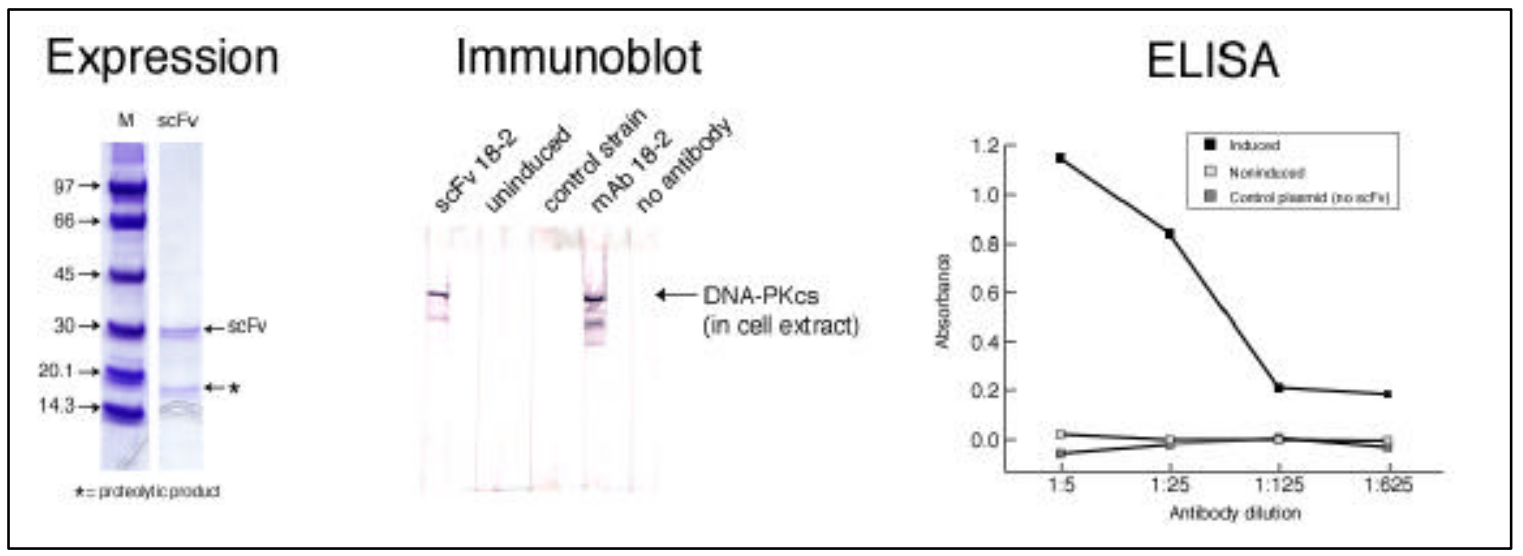


At the same time as we have been working with $\mathrm{scFv} 18-2$ to optimize protocols for purification and use of single chain antibodies, we have also been selecting new scFvs to use against targets specifically associated with DNA repair complexes. As a target, we have been using a small segment of a histone $\mathrm{H} 2 \mathrm{~A}$ variant, $\mathrm{H} 2 \mathrm{AX}$. This protein is specifically phosphorylated in cells exposed to ionizing radiation, and is thought to be involved in generating altered chromatin domains in the vicinity of double strand breaks. These experiments have been performed in collaboration with Dr. Ray Mernaugh of the Center for Molecular Recognition at Vanderbilt University, who has generously provided access to a large, combinatorial scFv library and who has carried out initial rounds of selection by phage display. The work has resulted in the identification of seven scFvs that have been further characterized in our laboratory. As shown, tight binding to the H2AX peptide can be shown in both ELISA and in surface plasmon resonance assays. As with scFv 18-2, these new scFvs are currently being tested in immunofluorescence assays.

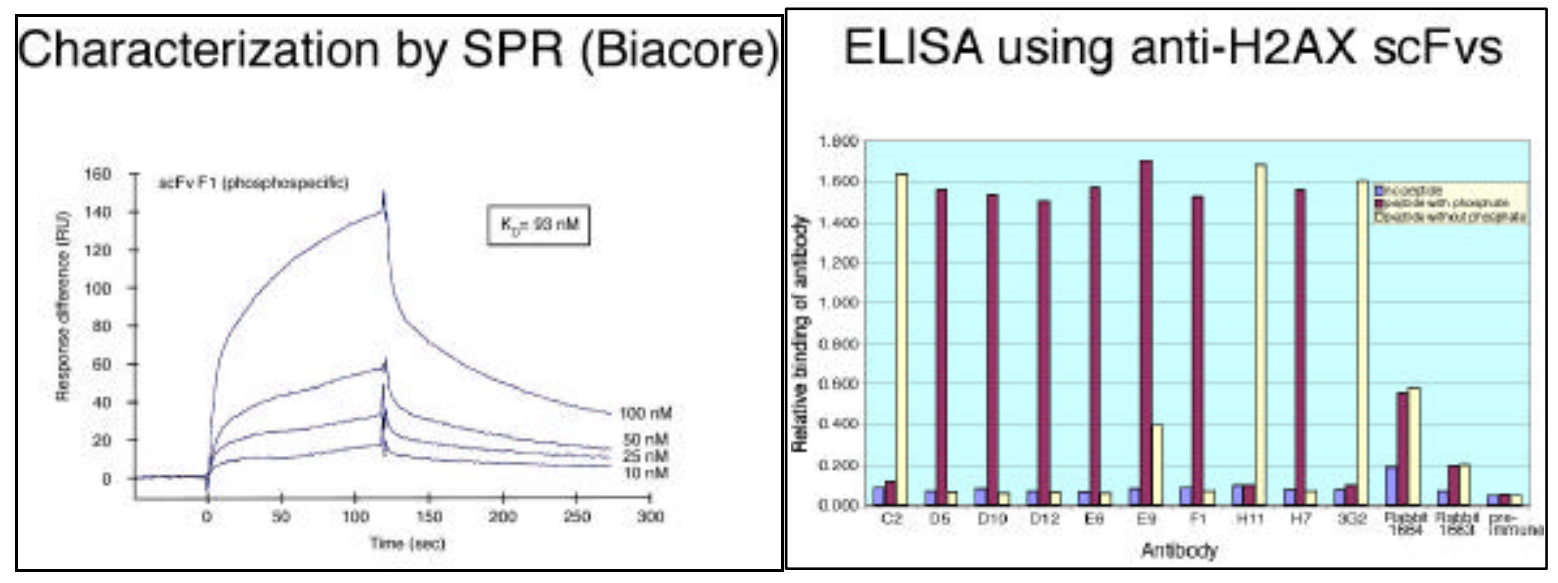

\section{Planned activities}

In the final year of the project, we will carry out immunofluorescence studies to demonstrate the utility of the scFvs, in combination with other antibodies, for in situ identification of repair complexes induced at low radiation doses.

\section{Information access}

Project results were presented at the Radiation Research Gordon conference in January, 2001, and will be presented at the DOE Low Dose Program/NASA workshop, to be held in Washington, D.C. in June, 2001. 